\title{
Healthcare Resource Utilization and Healthcare costs of patients infected with the SARS-CoV-2 virus in a tertiary care public hospital: A cross- sectional study in Thailand
}

Jirapong Leeyaphan

Bamrasnaradura Infectious Disease Institute

Charussi Leeyaphan

Mahidol University Faculty of Medicine Siriraj Hospital

Patama Sutha

Bamrasnaradura Infectious Disease Institute

Suthira Taychakhoonavudh

Chulalongkorn University Faculty of Pharmaceutical Sciences

Nattanichcha Kulthanachairojana ( $\nabla$ nattanichcha@go.buu.ac.th )

Burapha University Faculty of Pharmaceutical Sciences https://orcid.org/0000-0002-1590-5182

\section{Research Article}

Keywords: SARS-CoV-2, COVID-19, healthcare resource utilization, healthcare costs, Thailand

Posted Date: November 18th, 2020

DOI: https://doi.org/10.21203/rs.3.rs-110378/v1

License: (c) (i) This work is licensed under a Creative Commons Attribution 4.0 International License.

Read Full License 


\section{Abstract}

Background: Health care costs (HCCs) are a significant concern in developing countries. We investigated the healthcare resource utilization (HCRU) and HCCs for patients with COVID-19 concerning diseaseseverity and infection site.

Methods: We reviewed the data from electronic medical records of COVID-19 patients. We used comorbidity conditions and patient characteristics as covariates. Analyses were conducted using simple linear regression and generalized linear regression models with a log-link and gamma distribution.

Results: A total of 202 patients were confirmed to have a SARS-CoV-2 infection. Total costs per patient were USD 6,626 (USD 5,901-7,350). Personal protection equipment costs were the most significant cost for COVID-19 patients (USD 3,777). Mean medication costs per patient were USD 300 (USD 182-419). Patients with severe symptoms and a lower respiratory tract infection (LRI) had a higher cost and resource utilization value both before and after adjusting for covariates.

Conclusions: COVID-19 patients with severe symptoms and LRI were associated with higher HCRU. length of stay, severe symptoms, and LRI were associated with a higher cost of treatment.

\section{Background}

The Coronavirus infection outbreak began in China in late December $2019^{1}$. In Thailand, The Bamrasnaradura Infectious Diseases Institute, a referral-based public hospital responsible for emerging disease control, has taken care of the patients infected with the SARS-CoV-2 virus-SARS-CoV-2 was later referred to as COVID-19 by the World Health Organization (WHO). The literature reported that the mortality rate of the patients who were infected with the SARS-CoV-2 virus ranged from $1-12 \%$ in China ${ }^{2}, 8 \%$ in Iran ${ }^{3}$, and $39 \%$ in the United State of America (USA) ${ }^{4}$.

Health care costs (HCCs) are a significant concern in developing countries. The development of treatment cost models would be beneficial for the creation of effective health policies. For example, a novel avianorigin influenza $A(H 7 N 9)$ virus infection that was transmitted via the respiratory tract had a treatment cost model that was graded by disease severity. From the model for H7N9 infection in China, the mean cost was USD 1619 for mild patients, USD 22,292 for severe cases without death, and USD 32,956 for severe cases with death ${ }^{5}$. Focusing on the direct cost of hospitalization, the medication fees were the most significant contributors to both HCCs and the total fees correlated with disease severity ${ }^{6}$. Additionally, from the model for severe acute respiratory syndrome (SARS), days of hospitalization, disease severity, stage of the disease break-out, patient's occupation, baseline disease status, and medical insurance status had also affected the medical cost of confirmed cases ${ }^{7}$.

Concerning COVID-19 infection, a simulation model from the USA demonstrated that one symptomatic case could result in a median direct medical cost of USD $3045^{8}$; however, nowadays, no study has reported a direct medical cost of COVID-19 cases in a developing country while also including a treatment 
model. In this retrospective study, we investigated healthcare resource utilization (HCRU) and HCCs for patients with COVID-19 concerning disease-severity and infection site.

\section{Methods}

\section{Study population}

We reviewed the data obtained from the electronic medical records of patients who were admitted to the Bamrasnaradura Infectious Diseases Institute from January 2020 to April 2020. All patients had at least one confirmed SARS-CoV-2 diagnosis using a Real-Time-Polymerase-Chain-Reaction (RT-PCR). The treatments were independently prescribed by hospital physicians. The hospital discharge criteria included both clinical improvement and negative RT-PCR for SARS-CoV-2.

\section{Data Collection}

We collected demographic data including age, sex, and nationality, and underlying diseases. COVID-19 related data were collected, included duration of hospitalization, onset, and severity of the disease. The study protocol was approved by the institution review board from the Bamrasnaradura Infectious Diseases Institute before commencing our study. All procedures performed in this study were in accordance with the 1964 Helsinki declaration.

\section{Healthcare Costs And Healthcare Resources Utilization}

HCCs and HCRU of hospitalized patients with COVID-19 were categorized into 6 groups: 1 . Room; 2. Personal protection equipment (PPE); 3 . Treatment; 4. Investigation; 5 . Surgery and Nursing care; 6. Cleansing. We calculated HCRU and HCCs for all patients. HCRU was assessed in terms of medication, intravenous fluid, home medication, medical device cost, blood and blood components, and alternative medicine costs. The diagnostic investigations consisted of a radiologic examination, special investigation, ultrasonography, Computed Tomography, digital imaging, and pathological examinations. Surgery and nursing care included surgical devices, operative procedures, nursing care, dental care, and rehabilitation. HCCs were determined using the allowable amount remitted to providers on claims. HCCs were categorized as medication, oxygen therapy, blood transfusion, X-ray investigation, special investigation, medical devices, and procedures. The cost was converted from Thai baht to USD using the exchange rate: baht 31.03 to USD 1.

\section{Disease Severity And Respiratory Site Infection}

Patients with COVID-19 were grouped according to their severity of disease. Cases that had one of the following criteria were defined as having severe infection: 1 . Leafy lesions or lesion progress $>50 \%$ in $48 \mathrm{~h}$ indicated by X-ray chest radiograph; 2 . Dyspnea, breathing rate $>24$ times/minute; 3 . Severe hypoxemia, patients' Sp02 $\leq 9 \%$ under oxygen flow of 3-5 liters/minute; 4 . Shock, Acute Respiratory Distress Syndrome or Multiple Organ Dysfunction Syndrome ${ }^{9}$. Patients that did not fit these criteria were defined as mild cases. The respiratory infection sites were divided into upper and lower respiratory tract 
infections. Diagnoses such as the common cold, acute tracheobronchitis, and acute pharyngitis were considered as upper respiratory tract infections (URI), whereas pneumonia was considered a lower respiratory tract infection $(\mathrm{LRI})$.

\section{Statistical analysis}

Descriptive statistics were generated to describe the demographic and clinical characteristics by disease severity and infection site. Simple linear regression models were used for the analysis of HCRU and HCC outcomes. A generalized linear regression model with a log-link and gamma distribution was used for the analysis of HCCs. A p-value of less than 0.05 for the general linear regression analysis or other variables of known clinical relevance were included for further multiple linear regression analysis. A pvalue of less than 0.05 was considered statistically significant. The models used demographic (age, gender, nation, and comorbidity), length of stay (LOS), and clinical (disease severity and infection site) characteristics as covariates. All statistical analyses were performed using STATA version 12.

\section{Results}

\section{Demographic and Clinical Characteristics}

A total of 202 patients were considered with a mean age of 40.1 years old, and $41.6 \%$ of the patients were females with a confirmed SARS-CoV-2 infection during the study period. A total of 179 (88.6\%) patients presented with mild symptoms, whereas a total of $23(11.4 \%)$ cases presented with severe illness. Among the severe cases, four people had died. Pneumonia was the most common diagnosis (39.1\%), followed by the common cold (32.7\%), acute tracheobronchitis (15.8\%), and acute pharyngitis (12.4\%). The mean onset duration was 5.5 days. The total cost for overall patients were USD 6626.05. The PPE cost was the highest cost proportion among the total direct hospital cost (57\%). The mean LOS was 13.4 days. The demographic characteristics of patients were disease severity and infection site, as seen in Tables 1 and 2 , respectively. Patients with severe symptoms were older, $72.7 \%$ male, Thai nationality, with a higher comorbidity rate, longer LOS, and were more likely to have a LRI than when compared to patients with mild symptoms. Patients with LRI were older, $69.62 \%$ male, higher comorbidity rate, and a longer LOS than when compared to URI patients. Table 1 and Table 2 showed demographic and clinical characteristics of total patients. 
Table 1

Demographic characteristics of patients by disease severity.

\begin{tabular}{|lll|}
\hline \multirow{2}{*}{ Characteristic } & \multicolumn{2}{l|}{ Disease severity } \\
\cline { 2 - 3 } & Mild $(\mathbf{n}=\mathbf{1 8 0})$ & Severe $(\mathbf{n}=\mathbf{2 2})$ \\
\hline Age, mean (SD) & $38.7(14.8)$ & $51.9(14.4)$ \\
\hline Gender, Male & 56.7 & 72.7 \\
\hline Nation, Thai & 90 & 95.5 \\
\hline Diabetes mellitus & 2.8 & 36.4 \\
\hline Hypertension & 10 & 36.4 \\
\hline Dyslipidemia & 3.9 & 9.1 \\
\hline HIV infection & 0.6 & 4.6 \\
\hline Ischemic heart disease & 0.6 & 13.6 \\
\hline Lung disease & 0.6 & 9.1 \\
\hline Length of stay, mean (SD) & $12.6(8.1)$ & $20.6(10.3)$ \\
\hline Respiratory tract infection, Lower & 31.7 & 100 \\
\hline Values are percentage unless noted otherwise \\
\hline
\end{tabular}


Table 2

Demographic characteristics of patients by infection site.

\begin{tabular}{|lll|}
\hline Characteristic & \multicolumn{2}{l|}{ Respiratory tract infection site (RTI) } \\
\cline { 2 - 3 } & Upper RTI $(\mathbf{n}=123)$ & Lower RTI ( $\mathbf{n = 7 9 )}$ \\
\hline Age, mean (SD) & $33.9(12.5)$ & $49.7(14.3)$ \\
\hline Gender, Male & 51.2 & 69.6 \\
\hline Nation, Thai & 91.9 & 88.6 \\
\hline Diabetes mellitus & 2.4 & 12.7 \\
\hline Hypertension & 4.9 & 25.3 \\
\hline Dyslipidemia & 3.3 & 6.3 \\
\hline HIV infection & 0.8 & 1.3 \\
\hline Ischemic heart disease & 0 & 5.1 \\
\hline Lung diseases & 0 & 3.8 \\
\hline Length of stay, mean (SD) & $11.8(8.4)$ & $15.9(8.5)$ \\
\hline Severe symptoms & 0 & 27.9 \\
\hline Values are percentage unless noted otherwise \\
\hline
\end{tabular}

\section{Healthcare Resource Utilization}

The simple linear regression analyses showed the proportion of healthcare resource usage adjusted by covariate as age, sex, nation, and comorbidity. The analyses compared mild and severe symptom patients (Table 3) and upper and lower respiratory tract infection patients (Table 4), respectively. Before and After adjusting by covariate, patients with severe symptoms and LRI were associated with a higher proportion of resource usage and longer LOS when compared to mild symptom patients and URI except for patients that used chloroquine and home medications often used by patients with mild symptoms. 
Table 3

Proportions of COVID-19 patients using healthcare resources by disease severity.

\begin{tabular}{|c|c|c|c|c|}
\hline \multirow[t]{3}{*}{ Healthcare resource } & \multicolumn{4}{|l|}{ Severity } \\
\hline & \multicolumn{2}{|c|}{ Mild $(n=180)$} & \multicolumn{2}{|c|}{ Severe $(n=22)$} \\
\hline & Unadjusted & Adjusted & Unadjusted & Adjusted \\
\hline Antibiotic & $25.6^{\star}$ & $28.8^{*}$ & $90.9 *$ & $90.5^{\star}$ \\
\hline Antivirus & $47.2^{\star}$ & $49.3^{*}$ & $100 *$ & $100^{\star}$ \\
\hline Chloroquine & $49.4^{\star}$ & $51.3^{*}$ & $68.2^{\star}$ & $33.3^{\star}$ \\
\hline Hydroxychloroquine & $13.9 *$ & $13.6^{\star}$ & $59.1 *$ & $57.8^{*}$ \\
\hline Oxygen therapy & $10 *$ & $12.2^{\star}$ & $95.5^{\star}$ & $100^{*}$ \\
\hline Medication & $97.2^{\star}$ & $98^{*}$ & $100^{\star}$ & $100 *$ \\
\hline Home medication & $53.9 *$ & $57.8^{*}$ & $50^{\star}$ & $51.4^{\star}$ \\
\hline Blood transfusion & 0 & 0 & 13.6 & 12.2 \\
\hline X-ray investigation & $95^{\star}$ & $95.6^{*}$ & $100 *$ & $100 *$ \\
\hline Special investigation & $7.8^{*}$ & $7.4^{\star}$ & $36.4^{\star}$ & $25.1^{\star}$ \\
\hline Medical devices & $91.7 *$ & $92.4^{*}$ & $100 *$ & $100^{\star}$ \\
\hline Procedures & 0.6 & 0.5 & 36.4 & 13.9 \\
\hline LOS, mean (SD) & $12.6(8.1)^{\star}$ & $12.9(0.6)$ * & $20.6(10.3)^{\star}$ & $18.2(2.9)$ * \\
\hline \multicolumn{5}{|c|}{ Values are percentage unless noted otherwise, LOS; length of stay } \\
\hline \multicolumn{5}{|c|}{$\begin{array}{l}\text { Covariate adjusted (Age, Sex, Nation, Comorbidity (diabetes, hypertension, dyslipidemia, ischemic } \\
\text { hearth disease, human immunodeficiency virus infection, lung other diseases) }\end{array}$} \\
\hline \multicolumn{5}{|c|}{ * Statistically significant $(p<0.05)$} \\
\hline
\end{tabular}


Table 4

Proportions of COVID-19 patients using healthcare resources by respiratory tract infection (RTI) infection site.

\begin{tabular}{|c|c|c|c|c|}
\hline \multirow[t]{3}{*}{ Healthcare resource } & \multicolumn{4}{|c|}{ Respiratory tract infection site (RTI) } \\
\hline & \multicolumn{2}{|c|}{ Upper RTI ( $n=123)$} & \multicolumn{2}{|c|}{ Lower RTI (n = 79) } \\
\hline & Unadjusted & Adjusted & Unadjusted & Adjusted \\
\hline Antibiotic & $17.9 *$ & $20 *$ & $55.7 *$ & $54.7 *$ \\
\hline Antivirus & $29.3^{*}$ & $34.2^{*}$ & $89.9 *$ & $88.5^{\star}$ \\
\hline Chloroquine & $41.5^{\star}$ & $42.1^{\star}$ & $67.1^{*}$ & $62.1^{\star}$ \\
\hline Hydroxychloroquine & $11.4^{\star}$ & $12.6^{*}$ & $30.4^{*}$ & $32.8^{*}$ \\
\hline Oxygen therapy & $0.8^{*}$ & $1.4^{*}$ & $48.1^{*}$ & $43.7^{*}$ \\
\hline Medication & $95.9 *$ & $97.1^{\star}$ & $100 *$ & $100 *$ \\
\hline Home medication & $49.6^{\star}$ & $50.7^{\star}$ & $59.5^{\star}$ & $54.9 *$ \\
\hline Blood transfusion & 0 & 0 & 3.8 & 1.3 \\
\hline X-ray investigation & $92.7 *$ & $93^{*}$ & $100 *$ & $100 *$ \\
\hline Special investigation & $4.9^{*}$ & $8.7^{\star}$ & $20.3^{*}$ & $20.3^{*}$ \\
\hline Medical devices & $91.9 *$ & $92.2^{*}$ & $93.7 *$ & $94.9 *$ \\
\hline Procedures & 0.8 & 0.3 & 3.8 & 2.3 \\
\hline LOS, mean (SD) & $11.8(8.4)^{\star}$ & $11(0.8)$ * & $15.9(8.5)^{*}$ & $15.2(1.1)$ * \\
\hline \multicolumn{5}{|c|}{ Values are percentage unless noted otherwise, LOS; length of stay } \\
\hline \multicolumn{5}{|c|}{ Covariate adjusted (Age, Sex, Nation, Comorbidity (DM HT DLP HIV IHD Lung Other disease) } \\
\hline * Statistically significa & $<0.05)$ & & & \\
\hline
\end{tabular}

\section{Healthcare Costs}

The total costs per patient were USD 6626 (USD 5901-7350). The PPE costs were the most significant cost for COVID-19 patients (USD 3777). The mean medication costs per patient were USD 300 (USD 182419). For both patients with severe symptoms and LRI patients, there was an increase in HCCs compared to patients with mild symptoms and URI patients. Generalized linear modeling with a gamma distribution and log-link was used to assess the importance of covariate (age, sex, nation group, and comorbidity), onset, LOS, disease severity, and respiratory tract infection (Table 5). Age, sex, nationality, onset, and comorbidity were not found to be significant predictors of HCCs once LOS, disease severity, and RTI were accounted for. 
Table 5

Multivariate generalized linear modeling.

\begin{tabular}{|c|c|c|c|}
\hline Factors & $\begin{array}{l}\text { Coefficient } \\
\text { (SE) }\end{array}$ & $\begin{array}{l}\text { Relative increase in costs associated with variable } \\
\text { (baseline }=1 \text { ) }\end{array}$ & $\begin{array}{l}P \\
\text { Value }\end{array}$ \\
\hline Age & $\begin{array}{l}-0.0018 \\
(0.0015)\end{array}$ & -1.18 & 0.239 \\
\hline Sex* & $\begin{array}{l}0.0156 \\
(0.0374)\end{array}$ & 0.42 & 0.677 \\
\hline Nation group ${ }^{\star \star}$ & $\begin{array}{l}-0.0387 \\
(0.0629)\end{array}$ & -0.61 & 0.539 \\
\hline Onset & $\begin{array}{l}-0.0052 \\
(0.0039)\end{array}$ & -1.34 & 0.181 \\
\hline LOS & $\begin{array}{l}0.0670 \\
(0.0025)\end{array}$ & 26.76 & 0.000 \\
\hline Diabetes mellitus & $\begin{array}{l}-0.0359 \\
(0.0930)\end{array}$ & -0.39 & 0.700 \\
\hline Hypertension & $\begin{array}{l}-0.0019 \\
(0.0714)\end{array}$ & -0.03 & 0.978 \\
\hline Dyslipidemia & $\begin{array}{l}0.0515 \\
(0.1004)\end{array}$ & 0.51 & 0.608 \\
\hline HIV infection & $\begin{array}{l}0.1169 \\
(0.1848)\end{array}$ & 0.63 & 0.527 \\
\hline $\begin{array}{l}\text { Ischemic heart } \\
\text { disease }\end{array}$ & $\begin{array}{l}-0.2292 \\
(0.1540)\end{array}$ & -1.49 & 0.137 \\
\hline Lung disease & $\begin{array}{l}-0.1512 \\
(0.1563)\end{array}$ & -0.97 & 0.333 \\
\hline Other disease & $\begin{array}{l}-0.0960 \\
(0.0909)\end{array}$ & -1.06 & 0.291 \\
\hline 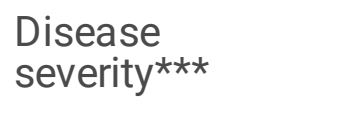 & $\begin{array}{l}0.2669 \\
(0.0721)\end{array}$ & 3.70 & 0.000 \\
\hline$\left.\mathrm{R}\right|^{\star \star \star \star}$ & $\begin{array}{l}0.2188 \\
(0.0474)\end{array}$ & 4.61 & 0.000 \\
\hline Constant & $\begin{array}{l}7.7279 \\
(0.0936)\end{array}$ & 82.63 & 0.000 \\
\hline \multicolumn{4}{|c|}{ LOS; length of stay, Rl; respiratory tract infection } \\
\hline * Baseline categor & nale. ** Base & category: Thai. & \\
\hline
\end{tabular}




\section{Discussion}

This study provides a cross-sectional view of HCCs and HCRU among COVID-19 patients attending a single center. HCCs and HCRU were described and analyzed based on disease severity and the respiratory tract infection site. The results showed a higher hospital resource consumption in severe COVID-19 symptom and LRI patients. This study demonstrated the association between total HCCs and LOS, disease severity, and respiratory tract infection site in hospitalized patients infected with COVID-19 in developing countries. PPE was the major HCC in COVID-19 patients. Patients with severe symptoms or LRI significantly utilized more healthcare resources. Neither antimicrobial nor anti-inflammation medication reduced the total cost.

Compared to H7N9, a major portion of the total direct medical cost of hospitalized patients infected with the H7N9 virus was medication, treatment, and laboratory testing $(80 \%)^{6}$. In contrast to COVID-19, the cost for PPE was the most significant portion of the total direct costs. This may be due to the uncertain transmission route of COVID-19 for the early pandemic period. Universal precaution with PPE resulted in no transmission between patients-healthcare workers in the hospital investigated. The cost of PPE was reduced after the transmission route and definite personal protection was established by the WHO.

The total days of hospital stay in this study were not different from the previous study ${ }^{2}$. In Thailand, all patients with COVID-19 had to be hospitalized for infectious control precautions. Negative PCR was required for discharge. LOS was related to PPE and room expenditures, which covered $74 \%$ of the direct medical costs of patients with COVID-19. A shortened LOS may decrease the cost; therefore, the discharging policy and outpatient management for patients with COVID-19 should be revised to reduce the hospital cost.

The mean direct medical costs of hospitalized COVID-19 patients were USD 5367 in URI cases and USD 8585 in LRI cases. All healthcare resources were significantly higher in LRI cases; however, compared to the total hospital cost per person in our study was lower than the total hospital cost per person in the USA (USD 14,366) ${ }^{8}$. Case management may be the main reason for this as all COVID-19 patients, including those who had mild symptoms, had to be admitted to the hospital. In the USA, a person who has mild symptoms were managed by either an in-person doctor visit or a telephone consultation, which costs about USD 57-96. Cases with mild symptoms or URI should be managed as outpatients to reduce total costs per person, and a policy to enforce this may be important to decrease the health economic burden from the COVID-19 disease.

There are a few limitations in this study. The inconsistent treatment protocol or ineffective medication was used in the early pandemic period, which impacted the treatment cost. The hospital setting in this study was a referral hospital for severe cases, which influences the high direct medical costs.

\section{Conclusions}


In conclusion, HCCs of patients with COVID-19 were significantly associated with LOS, respiratory site infection, and disease severity. LRI and severe symptom patients consume more HCRU. PPE was the main expenditure in the total cost. A specific precaution protocol and outpatient management may decrease the economic burden of COVID-19.

\section{Abbreviations}

HCCs - Health care costs

HCRU - Healthcare resource utilization

H7N9 - Avian-origin influenza A

LOS - Length of stay

LRI - Lower respiratory tract infection

PPE - Personal protection equipment

RTI - Respiratory tract infection

SARS - Severe acute respiratory syndrome

URI - Upper respiratory tract infection

USA - United State of America

WHO - World Health Organization

\section{Declarations}

\section{Ethics approval and Consent to participate}

The study protocol was approved by the institution review board from the Bamrasnaradura Infectious Diseases Institute (Reference number S010h/63_ExPD) before commencing our study. There was no consent to participate because our study was a retrospective cohort study and the ethical committee allow not to do the consent.

\section{Consent for publication}

Nattanichcha Kulthanachairojana hereby declare that I participated in the study and in the development of manuscript titled Healthcare Resource Utilization and Healthcare costs of patients infected with the SARS-CoV-2 virus in a tertiary care public hospital: A cross-sectional study in Thailand. I have read the final version and give my consent for the article to published in Infectious Disease of Poverty. 
Availability of supporting data

The datasets used and/or analysed during the current study are available from the corresponding author on reasonable request.

\section{Competing interests}

The authors declare that they have no competing interests

\section{Funding}

Faculty of Pharmaceutical Sciences, Burapha University, Chonburi, Thailand. where the funder did not take their role on study design, data collection, data interpretation, data analysis, or manuscript writing.

\section{Authors' contributions}

Jirapong Leeyaphan: Conceived and designed the analysis, Collected the data

Charussri Leeyaphan: Wrote the paper

Patama Sutha: Collected the data

Suthira Taychakhoonavudh: Performed the analysis

Nattanichcha Kulthanachairojana: Performed the analysis, Wrote the paper

\section{Acknowledgement}

We acknowledge Apichart Vachiraphan, Director of Bamrasnaradura Infectious Diseases Institute, Department of Diseases Control, Ministry of Public Health, Nonthaburi, Thailand, for administrative support.

\section{Authors' information}

1. Jirapong Leeyaphan

Bamrasnaradura Infectious Diseases Institute, Department of Disease Control, Ministry of Public Health, Nonthaburi, Thailand

E-mail address: Lekortho@gmail.com

2. Charussri Leeyaphan

Department of Dermatology, Faculty of Medicine Siriraj Hospital, Mahidol University, Bangkok, Thailand E-mail address: Charussri.lee@mahidol.ac.th 


\section{Patama Sutha}

Bamrasnaradura Infectious Diseases Institute, Department of Disease Control, Ministry of Public Health, Nonthaburi, Thailand

E-mail address: mueyeing64@gmail.com

\section{Suthira Taychakhoonavudh}

Department of Social and Administrative Pharmacy, Faculty of Pharmaceutical Sciences, Chulalongkorn University, Bangkok, Thailand.

E-mail address: Suthira.t@chula.ac.th

5. Nattanichcha Kulthanachairojana (corresponding author)

Department of Social and Administrative Pharmacy, Faculty of Pharmaceutical Sciences, Burapha University, Chonburi, Thailand.

169 Longhadbangsaen Rd, Sansuk Distract, Chonburi, Thailand 10130

E-mail address: nattanichcha@go.buu.ac.th

Tel: +668-2696-3561

\section{References}

1. Guan WJ, Ni ZY, Hu Y, et al. Clinical Characteristics of Coronavirus Disease 2019 in China. N Engl J Med. 2020.

2. Mizumoto K, Chowell G. Estimating Risk for Death from Coronavirus Disease, China, JanuaryFebruary 2020. Emerging infectious diseases. 2020;26(6):1251-1256.

3. Shahriarirad R, Khodamoradi Z, Erfani A, et al. Epidemiological and clinical features of 2019 novel coronavirus diseases (COVID-19) in the South of Iran. BMC Infect Dis. 2020;20(1):427.

4. Cummings MJ, Baldwin MR, Abrams D, et al. Epidemiology, clinical course, and outcomes of critically ill adults with COVID-19 in New York City: a prospective cohort study. Lancet. 2020;395(10239):17631770.

5. Qi X, Jiang D, Wang H, et al. Calculating the burden of disease of avian-origin H7N9 infections in China. BMJ open. 2014;4(1):e004189.

6. Huo X, Chen LL, Hong L, et al. Economic burden and its associated factors of hospitalized patients infected with A (H7N9) virus: a retrospective study in Eastern China, 2013-2014. Infectious diseases of poverty. 2016;5(1):79. 
7. Xiao F, Chen BW, Wu YF, et al. [Analysis on the cost and its related factors of clinically confirmeds severe acute respiratory syndrome cases in Beijing]. Zhonghua liu xing bing xue za zhi = Zhonghua liuxingbingxue zazhi. 2004;25(4):312-316.

8. Bartsch SM, Ferguson MC, McKinnell JA, et al. The Potential Health Care Costs And Resource Use Associated With COVID-19 In The United States. Health Aff (Millwood). 2020;39(6):927-935.

9. Gao HN, Lu HZ, Cao B, et al. Clinical findings in 111 cases of influenza A (H7N9) virus infection. The New England journal of medicine. 2013;368(24):2277-2285. 